\title{
Microdochium tabacinum, Confirmed as a Pathogen of Alfalfa in Gansu Province, China
}

\author{
Zhaohui Wen, State Key Laboratory of Grassland Agro-Ecosystems; College of Pastoral Agricultural Science and Technology, Lan- \\ zhou University; and Central Laboratory of Technical Center, Gansu Exit-Entry Inspection and Quarantine Bureau; Lanzhou 730010, \\ P. R. China; and Tingyu Duan, Michael J. Christensen, and Zhibiao Nan, State Key Laboratory of Grassland Agro-Ecosystems; Col- \\ lege of Pastoral Agricultural Science and Technology, Lanzhou University
}

\begin{abstract}
Wen, Z., Duan, T., Christensen, M. J., and Nan, Z. 2015. Microdochium tabacinum, confirmed as a pathogen of alfalfa in Gansu Province, China. Plant Dis. 99:87-92.

A crown and root rot complex was detected in the alfalfa (Medicago sativa 'Longdong') fields of Huanxian County. The symptoms of the diseased plants were characterized, and 11 fungal species were obtained from the roots. These fungi included isolates that resembled the genus Microdochium. An isolate of this type, designated MP313, was proven to infect alfalfa, fulfilling Koch's postulates. Isolate MP313 was examined by microscopy and the morphological characteristics indicated that it was similar to members of the genus Microdochium. Sequence analyses of the $28 \mathrm{~S}$ large subunit as well as the internal tran-

revealed 98 to $100 \%$ similarity to the corresponding regions of $M$. tabacinum. A polymerase chain reaction assay based on the ITS region of the rDNA was developed to amplify a 304-bp fragment from DNA concentrations as low as $20 \mathrm{fg} / \mu \mathrm{l}$, which was sensitive enough to detect isolate MP313 in diseased root samples. Taken together, these results confirmed that $M$. tabacinum was one of a complex of fungi associated with crown and root rot in the alfalfa samples collected in Gansu Province. This is the first report of M. tabacinum being a pathogen of alfalfa in China.
\end{abstract} scribed spacer (ITS) region of the ribosomal DNA (rDNA) of MP313
Alfalfa (Medicago sativa L.), also commonly known as lucerne, is a highly nutritious animal feed and globally is one of most important forage crops $(27,34)$. Alfalfa is a versatile crop that can be grown in a wide range of soils and under various climatic conditions. The plant plays an important role in crop rotation and is a good green manure, which can alleviate the effects of water and wind erosion as well as having positive effects on soil fertility, soil structure, and soil health $(12,22)$. In north China, alfalfa is planted on a large scale to provide feed for grazing animals throughout the year. The cultivated area of alfalfa in Gansu Province in 2013 was estimated to be 650,000 ha. Given the scale of production, losses due to disease could have a huge economic impact (30).

The crown and root rot complex is known to be a limiting factor to alfalfa production throughout the world $(19,26)$. In China, this disease was first reported in the Xinjiang Province in 1989 (8). This study, conducted by Chen et al. (8), demonstrated that Rhizoctonia solani and Fusarium spp. were the causal organisms. A subsequent study also reported incidents of alfalfa crown and root rot diseases in Gansu Province in 1994 (29), although specific causal organisms were not identified. The symptoms of crown and root rot complex include discoloration of infected tissues, the development of brown and rotted areas on the root and crown tissues, and, sometimes, the death of the entire plant. Consequently, infection significantly reduces the growth, yield, and longevity of alfalfa stands (24). Several plant-pathogenic fungi have been isolated from rotted root and crown tissues; the most frequently isolated belonging to the genus Fusarium $(4,5,9,16,18,25)$, although other genera, including Phoma $(1,16)$, Pythium $(5,16)$, Rhizoctonia $(8,14-16,30)$, and Thielaviopsis (3), have also been reported. However, despite these numerous reports, a detailed understanding of the fungi responsible for the crown and root rot complex has yet to

Corresponding author: Zhibiao Nan, E-mail: zhibiao@ lzu.edu.cn

Accepted for publication 20 June 2014.

http://dx.doi.org/10.1094/PDIS-10-13-1048-RE

(C) 2015 The American Phytopathological Society be confirmed. Furthermore, it has been suggested that the crown and root rot complex probably differs according to geographical area, environmental conditions, and cultural practices $(16,35)$. Consequently, it is essential to identify the local causal organisms before successful disease management strategies can be developed for a particular region.

With the area of alfalfa cropping growing in China and global climate changes, the risk of yield losses due to disease is increasing. There is also the possibility that new pathogens will bring additional problems in alfalfa production. However, a better understanding of current disease problems is also required to develop effective disease management procedures. The current study focuses on the crown and root rot disease detected in the alfalfa ('Longdong') fields of Huanxian County, Gansu Province in June 2012. The disease exhibited browning of the lower stem and tap root, while the aboveground symptoms included stunting and yellowing. The objectives of the research were to determine the composition of fungi isolated from the crowns and roots of collected plants and to utilize both molecular and microbiological approaches to identify the causal organisms responsible for the crown and root rot disease and provide fundamental work leading to disease management.

\section{Materials and Methods}

Collection of samples. Samples of diseased alfalfa were collected in June of 2012, which corresponded to the flowering growth stage (stage 5/6) (13). In total, 94 alfalfa plants exhibiting rotted lesions on either their crowns or roots were selected randomly for analysis. The samples originated from six alfalfa fields located in Quzi town $\left(107^{\circ} 21^{\prime} \mathrm{E}, 36^{\circ} 20^{\prime} \mathrm{N}\right.$, elevation 1,163 m) and were representative of the entire area under alfalfa production in Huanxian County in Gansu Province. The collection sites experience an average temperature of $9.2^{\circ} \mathrm{C}\left(-23.2\right.$ to $\left.37.5^{\circ} \mathrm{C}\right)$ and $450 \mathrm{~mm}$ of rainfall, which occurs mainly during the summer months, July to September. The samples were air dried (approximately $20^{\circ} \mathrm{C}$ ) and stored at $4^{\circ} \mathrm{C}$ prior to analysis.

Fungal isolation. After removing the leaves from each sample, the crown and root tissues were washed under running tap water to remove soil. Five sections (approximately $5 \mathrm{~mm}$ in length) were 
cut from the margins of the lesions of each sample and surface sterilized in $75 \%$ ethanol for $2 \mathrm{~min}$ and $1 \%$ sodium hypochlorite for $5 \mathrm{~min}$ (28). The five sections were subsequently rinsed five times in sterile distilled water, blotted on sterilized filter paper, and placed equidistant in a single $90-\mathrm{mm}$ petri dish containing potato dextrose agar (PDA; Oxoid Ltd., Basingstoke, Hampshire, England) amended with streptomycin $(50 \mu \mathrm{g} / \mathrm{ml})$. The samples were incubated at $22^{\circ} \mathrm{C}$ in the dark for 7 to 14 days. The fungal colonies that developed from the sections were examined by microscopy. Each distinct colony was subcultured on fresh PDA plates and incubated for an additional 7 to 14 days. Single-spore or hyphal-tip subcultures were isolated and maintained on PDA slants. Fungal species from each plant were recorded to determine frequency of isolation of each fungus from different plants. Representative isolates were maintained at $4^{\circ} \mathrm{C}$ or stored as lyophilized mycelium at $-20^{\circ} \mathrm{C}$.

Morphological characterization. The fungi isolated were initially identified based on their morphological and cultural characteristics, according to Domsch et al. (11), Booth (6), and Nelson et al. (31). The descriptions of Simmons and Roberts (39) and Latunde-Dada et al. (23) were also consulted when necessary. The morphological characteristics of the fungi were examined by light microscopy using an Olympus BH-2 microscope (Olympus, Center Valley, PA) at $\times 600$ magnification.

One of the fungi isolated from diseased alfalfa plants, a Microdochium-like fungus of which isolate MP313 is typical, was unknown in Chinese disease records for this plant species; therefore, this fungus was subjected to a detailed examination. Cultures were grown in darkness at $25^{\circ} \mathrm{C}$ and the colony diameters measured daily for 1 week. The growth rate was calculated as the 7-day average of mean daily growth (millimeters per day). Three cultures of isolate MP313 were investigated and the experiments were conducted twice.

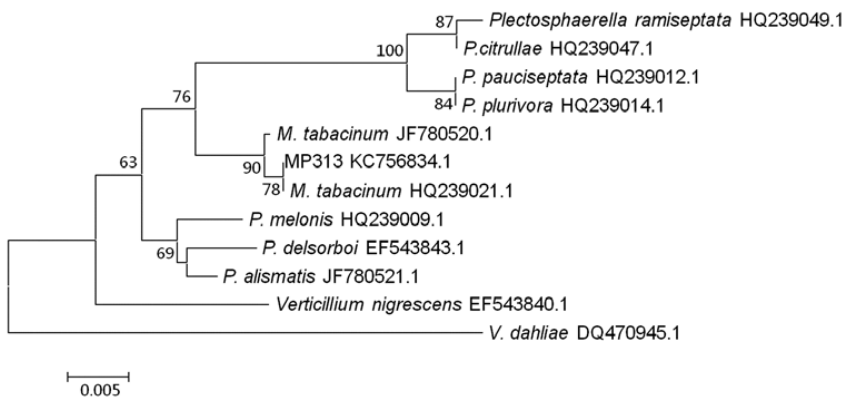

Fig. 1. Phylogenetic tree comparing the nucleotide sequences from the large subunit region of Microdochium tabacinum isolate MP313 and other closely related fungi. Confidence values on the branches were obtained from 1,000 bootstrap replicates.

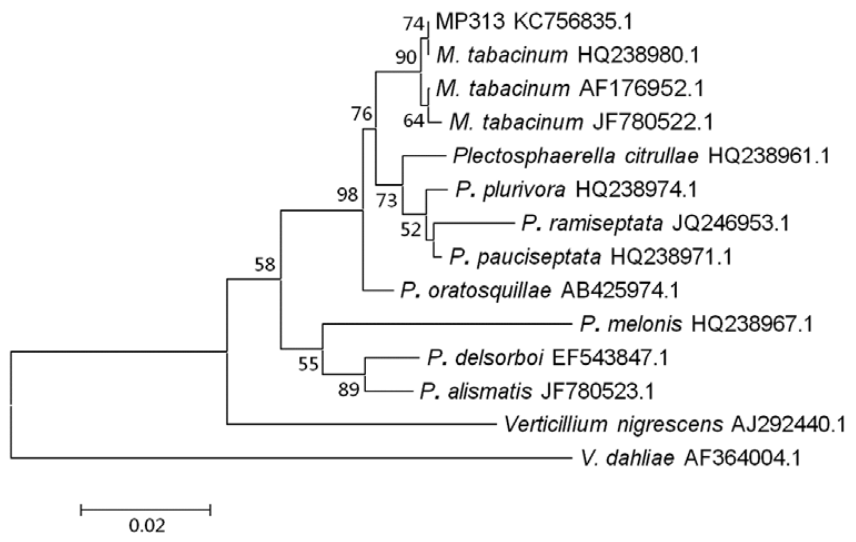

Fig. 2. Phylogenetic tree comparing the nucleotide sequences from the internal transcribed spacer ribosomal DNA region of Microdochium tabacinum isolate MP313 and other closely related fungi. Confidence values on the branches were obtained from 1,000 bootstrap replicates.
Molecular characterization of isolate MP313. Microdochiumlike isolate MP313 was selected for generating its internal transcribed spacer (ITS) ribosomal DNA (rDNA) and 28S nrDNA sequences. Single-conidium isolates were grown in $200 \mathrm{ml}$ of potato dextrose broth (PDB) (Oxoid Ltd.) liquid cultures on a rotary shaker $(130 \mathrm{rpm})$ at $25^{\circ} \mathrm{C}$ for 7 days. The mycelia were harvested by vacuum filtration and freeze-dried, and the genomic DNA was extracted from lyophilized samples using the E.Z.N.A. Fungal DNA Kit (Omega Bio-Tek, Doraville, GA), according to the manufacturer's protocol. The ITS and large subunit (LSU) regions were amplified using the primer pairs ITS4 and ITS5 (45) and LR5 and LROR (43), respectively. The $25-\mu \mathrm{l}$ reaction mixtures containing $10 \mathrm{pmol}$ of each primer, $0.625 \mathrm{U}$ of Taq DNA polymerase (Takara Corp., Dalian, China), $0.25 \mathrm{mM}$ dNTP, $1 \times$ polymerase chain reaction (PCR) buffer, and $20 \mathrm{ng}$ of template DNA were processed in a GenAmp 9700 thermocycler (Applied Biosystems, Foster City, CA) using the following protocol: $94^{\circ} \mathrm{C}$ for $2 \mathrm{~min}$; followed by 35 cycles of $95^{\circ} \mathrm{C}$ for $30 \mathrm{~s}, 55^{\circ} \mathrm{C}$ for $45 \mathrm{~s}$, and $72^{\circ} \mathrm{C}$ for $50 \mathrm{~s}$; followed by a final extension at $72^{\circ} \mathrm{C}$ for $10 \mathrm{~min}$.

Following electrophoresis, the PCR products were purified using a gel DNA purification system (Takara Corp.). The recovered PCR products were sequenced by GENEWIZ Inc. (Beijing) using the primers from the original PCR reactions to sequence in both directions. The resulting sequence data were edited using the BioEdit software package (17).

A multiple sequence alignment was created using the CLUSTAL_X program (42) to compare the sequence data from the $\mathrm{Mi}$ crodochium-like isolate MP313 with the corresponding sequences of several species of Microdochium (7), including three isolates of Microdochium tabacinum, as well as two species of Verticillium (Figs. 1 and 2). Phylogenetic analyses were performed using the neighbor-joining method (37) and the MEGA version 4.0 program (41), with the statistical validity of the phylogenic relationships being tested via bootstrap analysis (1,000 reps). Having confirmed that MP313 was a novel isolate of $M$. tabacinum, its ITS-rDNA and 28S nrDNA sequences were submitted to GenBank as KC756835.1 and KC756834.1, respectively.

Pathogenicity tests. The pathogenicity of M. tabacinum MP313 on alfalfa was assessed in two ways. Culture plate trials were performed to test its virulence against a range of host seedlings (Table 1), including five alfalfa cultivars ('Algonquin', Longdong, 'Hunter River', 'Sitel', and 'Gannong No. 3') and five cucurbits, in view of the use of alfalfa as a break-crop in rotation with cucurbits in Huanxian County: cucumber (Cucumis sativus 'Z9343'), pumpkin (Cucurbita pepo 'Alanyidai'), squash (Cucurbita moschata

Table 1. Pathogenicity of Microdochium tabacinum isolate MP313 in a range of hosts, including five alfalfa cultivars and a variety of cucurbits ${ }^{\mathrm{z}}$

\begin{tabular}{lcc}
\hline Host & DSI & DI $(\%)$ \\
\hline Medicago sativa & \\
Algonquin & $51.3 \mathrm{~d}$ & $82.38 \mathrm{ef}$ \\
Longdong & $33.1 \mathrm{f}$ & $84.88 \mathrm{e}$ \\
Hunter river & $70.3 \mathrm{~b}$ & $92.25 \mathrm{~d}$ \\
Sitel & $73.5 \mathrm{~b}$ & $97.50 \mathrm{ab}$ \\
Gannong No. 3 & $42.3 \mathrm{e}$ & $93.75 \mathrm{~cd}$ \\
Cucurbitaceae & & \\
Cucumis sativus Z9343 & $50.8 \mathrm{~d}$ & $92.50 \mathrm{~d}$ \\
Cucurbita pepo Alanyidai & $36.6 \mathrm{f}$ & $70.50 \mathrm{~h}$ \\
C. moschata Yongan No. 1 & $45.8 \mathrm{e}$ & $81.75 \mathrm{fh}$ \\
Cucumis melo Huanghemi & $61.0 \mathrm{c}$ & $95.50 \mathrm{bc}$ \\
Citrullus lanatus Xinda & $91.8 \mathrm{a}$ & $100.0 \mathrm{a}$ \\
\hline
\end{tabular}

${ }^{\mathrm{z}}$ Symptoms of infected seedlings were assessed after 15 days at $20^{\circ} \mathrm{C}$ using the 0 -to-4 scoring system of Altier and Thies (2), where $0=$ healthy, $1=$ primary root tip necrotic but firm, 2 = primary root tip rotted and soft, $3=$ dead seedling, and $4=$ dead seed. These values were used to calculate the disease severity index (DSI) as follows: $\%$ DSI $=\Sigma$ (numerical value of class $\times$ the number of individuals in a class)/(the expected number of germinated seeds $\times 4) \times 100$. The disease incidence $(D I)$ represents the mean number of seedlings exhibiting symptoms of infection. The same letters in the same row are not significantly different according to the least significant difference test $(P=0.05)$. 
'Yongan No. 1'), melon (Cucumis melo 'Huanghemi'), and watermelon (Citrullus lanatus 'Xinda'). The seed was surface sterilized by submersion in $70 \%$ ethanol for $1 \mathrm{~min}$ and then $5 \%$ sodium hypochlorite solution for $10 \mathrm{~min}$, rinsed three times in sterile water, and allowed to air dry on sterilized filter paper. The experiment was conducted according to the method of Altier and Thies (2), with the following modifications. A 5-mm plug of MP313 was taken from the edge of a 7-day-old colony grown on PDA and placed in the center of a $9-\mathrm{cm}$ petri dish containing $2 \%$ water agar (WA). After incubation at $20^{\circ} \mathrm{C}$ for 3 days, 10 surface-sterilized seeds were placed equidistant on the inoculated agar surface, and the plates were sealed with Parafilm (Pechiney Plastic Packaging, Chicago) to reduce desiccation. The plates were incubated in the dark at $20^{\circ} \mathrm{C}$ for 15 days. Noninoculated controls were included in all the experiments. There were four replicate plates for each treatment and we conducted this procedure twice at different times. For the rest of the fungi listed in Table 2, we did the pathogenicity test with Algonquin alfalfa as described above. The disease incidence (percentage of infected seedlings) was recorded and the disease symptoms rated using the 0 -to- 4 scale of Altier and Thies (2), where $0=$ healthy, $1=$ primary root tip necrotic but firm, $2=$ primary root tip rotted and soft, $3=$ dead seedling, and $4=$ dead seed. A disease severity index (DSI) was calculated as follows: $\%$ DSI $=\Sigma$ (numerical value of class $\times$ the number of individuals in a class)/(the expected number of germinated seed $\times 4) \times 100$. The DSI data from the two repeat experiments for isolate MP313 were combined and the mean DSI calculated. Statistical analyses were performed using the SPSS software version 10.0 (SPSS Inc., Chicago). Fisher's least significance difference test was used to identify significant differences between the different treatment groups.

Greenhouse pathogenicity tests were also conducted by inoculating healthy alfalfa (Algonquin) seedlings by soil drenching (28). Seed of Algonquin were surface sterilized as described above and germinated by incubation at $20^{\circ} \mathrm{C}$ and $70 \%$ relative humidity (RH) for $24 \mathrm{~h}$ before uniform seedlings were selected for transplanting into plastic pots $(8 \mathrm{~cm}$ in diameter) filled with a peat/vermiculite mixture $(1: 1, \mathrm{vol} / \mathrm{vol})$ that had been autoclaved three times for $1 \mathrm{~h}$ at $121^{\circ} \mathrm{C}$, and grown in a greenhouse $\left(18\right.$ to $22^{\circ} \mathrm{C}, 16 \mathrm{~h}$ photoperiod, $60 \% \mathrm{RH}$ ) for 10 days. Conidia were collected from 3-week-old PDA cultures of $M$. tabacinum by adding $3 \mathrm{ml}$ of sterile distilled water and scraping gently across the mycelia surface with a sterile glass rod. The conidial suspension was filtered through four layers of sterile muslin to remove the fungal hyphae and adjusted to $10^{6}$ conidia/ml using a hemocytometer, before being used to inoculate the potted seedlings by uniformly drenching the soil with $20 \mathrm{ml}$ of the resulting suspension. The noninoculated control plants were treated with $20 \mathrm{ml}$ of sterile distilled water. The plants were returned to the greenhouse for 3 weeks before being assessed for symptoms of disease according to the 0 -to- 4 scale of Hwang et al., (20), where $0=$ no disease, $1=$ small lesions on root, $2=$ large lesions on root, $3=$ lesions covering more than one-half of the root circumference, and $4=$ lesions covering more than one-half of the

Table 2. Frequency of isolation of fungi from diseased crown and root of alfalfa in Huanxian County

\begin{tabular}{lcc}
\hline Fungus & Total isolates & Frequency $(\%)^{\mathbf{z}}$ \\
\hline Fusarium acuminatum & 11 & 6.5 \\
F. semitectum & 55 & 32.7 \\
F. oxysporum & 5 & 3 \\
F. avenaceum & 2 & 1.2 \\
F. equiseti & 22 & 13.1 \\
Phoma medicaginis & 23 & 13.7 \\
Alternaria alternata & 19 & 11.3 \\
Colletotrichum destructivum & 6 & 3.6 \\
Scopulariopsis brevicaulis & 10 & 6 \\
Penicillium sp. & 9 & 5.4 \\
Microdochium tabacinum & 6 & 3.6
\end{tabular}

${ }^{\mathrm{z}}$ Frequency (\%): the number of each pathogen isolated from alfalfa crowns or roots relative to the total number of fungi isolated. root cross-section. Each treatment consisted of 12 plants with four replications and the entire experiment was repeated three times.

A similar experiment was also performed to investigate the virulence of MP313 against mature alfalfa plants. In this case, 2month-old alfalfa plants (Algonquin) in 20-cm clay pots filled with a sterile peat/vermiculite mixture $(1: 1 . \mathrm{vol} / \mathrm{vol})$ were treated with $30 \mathrm{ml}$ of conidial suspension. Control plants were treated with 30 $\mathrm{ml}$ of sterile distilled water. Five plants were grown in each pot and there were four pots for each treatment. The plants were maintained and assessed as described above. To confirm the virulence of MP313, this experiment was conducted twice. Preliminary data analysis showed that the results of the two experimental runs were very similar; therefore, the data from both runs were combined for the final analysis.

Root samples were taken from symptomatic plants and subjected to the fungal isolation procedure described above to confirm that the observed disease symptoms were indeed caused by the infection and colonization of M. tabacinum isolate MP313.

Design of M. tabacinum-specific primers. A pair of M. tabacinum-specific primers was designed from the ITS sequence of the MP313 isolate (GenBank accession number KC756835). A BLAST search was performed using the MP313 sequence to identify homologous sequences from closely related sequences. The ITS database produced was used to compare potential target sequences to ensure that the primers were designed to a region specific to $M$. tabacinum. The resulting forward and reverse primers, which amplified a 304-bp fragment, were designated Mt1F and Mt1R and had the nucleotide sequences 5'-CGACGATAC TTCTGAGTGTTCT-3' and 5'-AATGCGAGGCTGATGCTA-3', respectively.

Sensitivity and specificity of the Mt1F-Mt1R primer set. Tenfold serial dilutions of $M$. tabacinum genomic DNA, ranging from $20 \mathrm{ng} / \mu \mathrm{l}$ to $2 \mathrm{fg} / \mu \mathrm{l}$, were used to test the sensitivity of the Mt1FMt1R primer set. The PCR reactions were performed in $25-\mu 1$ reaction volumes as described above but using a different PCR protocol: $94^{\circ} \mathrm{C}$ for $5 \mathrm{~min}$; followed by 35 cycles of $94^{\circ} \mathrm{C}$ for $30 \mathrm{~s}, 55^{\circ} \mathrm{C}$ for $30 \mathrm{~s}$, and $72^{\circ} \mathrm{C}$ for $30 \mathrm{~s}$; with a final extension at $72^{\circ} \mathrm{C}$ for 7 $\mathrm{min}$. The resulting PCR products were visualized by electrophoresis on $1 \%$ agarose gels stained with ethidium bromide at $0.5 \mu \mathrm{g} / \mathrm{ml}$.

The specificity of the primer set was tested using genomic DNA $(20 \mathrm{ng} / \mu \mathrm{l})$ from 11 fungal species commonly associated with the root rot of alfalfa in Gansu province $(16,25)$, including Fusarium acuminatum, $F$. equiseti, $F$. oxysporum, $F$. semitectum, $F$. avenaceum, Colletotrichum destructivum, Phoma medicaginis, R. solani, Alternaria alternata, Penicillium sp., and Scopulariopsis brevicaulis, as well as $M$. nivale and $M$. bolleyi. All the isolates were grown on PDA for 6 to 8 days before being transferred to liquid cultures, and their DNA was extracted as described above. The conditions of the PCR reactions were identical to those used for the sensitivity experiment. A separate experiment was also conducted using the ITS4 and ITS5 primer set as a positive control.

PCR amplification from alfalfa roots. Alfalfa (Algonquin) seedlings were grown in plastic pots in a sterile peat/vermiculite mixture $(1: 1, \mathrm{vol} / \mathrm{vol})$ for 10 days and inoculated with $20 \mathrm{ml}$ of MP313 conidial suspension, as described above. Symptomatic roots were tested for the presence of $M$. tabacinum by PCR. The roots of both inoculated and noninoculated plants were washed with distilled water and surface sterilized in $75 \%$ ethanol for $2 \mathrm{~min}$ before being rinsed three times with sterile deionized water. Approximately $0.1 \mathrm{~g}$ of root tissue was placed in a $1.5-\mathrm{ml}$ Eppendorf tube and ground in liquid nitrogen. The total DNA was extracted. The conditions of the PCR reactions were identical to those used for the sensitivity experiment. Genomic DNA from isolate MP313 and sterile MQ water were used as positive and negative controls, respectively.

\section{Results}

Fungal isolation. In total, 168 isolates were obtained from the discolored root or crown tissues of the diseased plants collected from the alfalfa fields, which belonged to 11 species of different 
fungi, including 9 plant pathogens as well as 2 saprophytic species (Penicillium sp. and S. brevicaulis). Fusarium spp., including $F$. acuminatum, $F$. equiseti, $F$. oxysporum, $F$. avenaceum, and $F$. semitectum, were the most frequently isolated, constituting $56.5 \%$ of the total number of isolates recovered. The frequency of the other pathogens ranged from 3.6 to $13.7 \%$, with the Microdochium-like isolates being recovered at a frequency of $3.6 \%$ (Table 2).

Morphological characterization of MP313. The Microdochium-like isolates formed moist, appressed, cream-colored, fungal colonies when grown on PDA media (Fig. 3a). Isolate MP313, which was selected randomly for further evaluation, grew at a rate of $2.9 \mathrm{~mm} /$ day in the dark at $25^{\circ} \mathrm{C}$. The mycelia of MP313 were hyaline and branched and formed hyphal coils, which produced short lateral conidiophores (Fig. 3c, g, and h). The conidiogenous cells were phialidic, hyaline, smooth, and sometimes produced a cylindrical collarette just below the apex (Fig. 3d-f, i, and j). The conidia were ellipsoidal, hyaline, and smooth (Fig. 3b), and were sometimes aggregated in slimy heads (Fig. 3c, d, and j). No chlamydospores were observed in any of the samples.

Molecular characterization of isolate MP313. The LSU and ITS sequences of isolate MP313 were compared with the sequences of M. tabacinum deposited at GenBank and determined to be 98 to $100 \%$ similar. The sequences of MP313 were used to search GenBank for similar sequences from other closely related species. The sequences obtained were used to construct phylogenetic trees (Figs. 1 and 2). The LSU tree included 9 members of the genus Microdochium and 1 from Verticillium, while the ITS tree had these 10 as well as an additional Verticillium sequence. The two trees produced similar patterns of branching and, in both cases, isolate MP313 clustered with M. tabacinum isolate Plec 11, with the two isolates being more similar to each other than to the other M. tabacinum isolate, CBS 13737 . These results validated the morphological characterization of MP313 and confirmed it to be an isolate of $M$. tabacinum.

Pathogenicity tests of isolate MP313 and other isolated fungal species. Fungi listed in Table 2 showed varied degrees of symptom severity on Algonquin. All fungi caused water-soaked lesions on the primary root tips and stem wilt (data not presented). Isolate MP313 was found to be pathogenic to all of the host plants (alfalfa cultivars and cucurbit species) in the culture plate trials (Table 1). The disease incidence (DI) and DSI varied among the alfalfa cultivars, with Sitel being the most sensitive, having a DI of $97.5 \%$ and a DSI of 73.5. Algonquin was found to have the lowest disease incidence $(82.38 \%)$ but exhibited moderate symptoms of disease (51.3), which usually became evident in the seedlings at 6

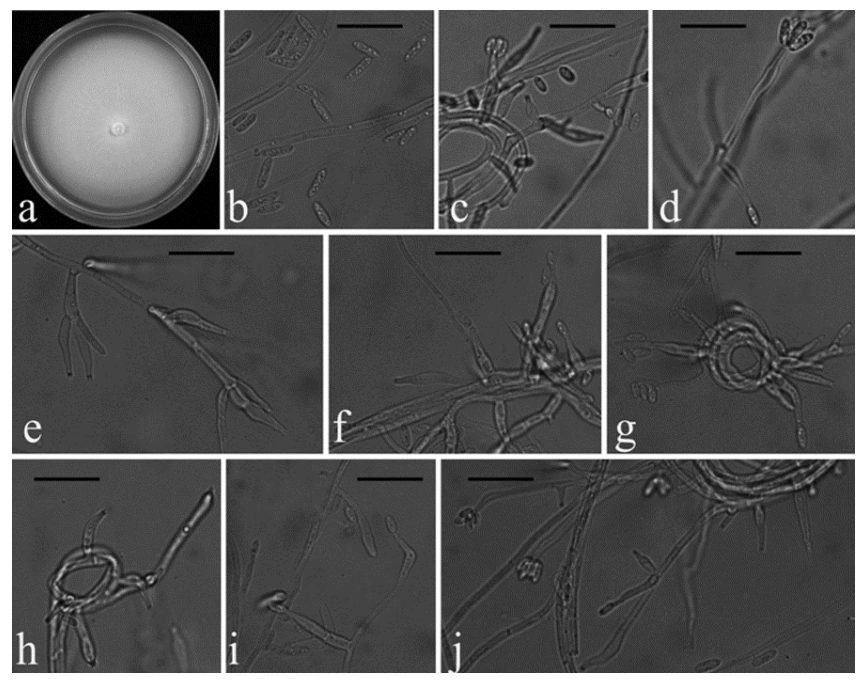

Fig. 3. Morphology of Microdochium tabacinum isolate MP313: a, colony on potato dextrose agar after 15 days of dark incubation at $25^{\circ} \mathrm{C} ; \mathbf{b}-\mathbf{j}$, micrographs showing b, conidia; c, g, and h, hyphal coils; and d-f, i, and j, phialides of MP313 on water agar after 10 days. Bars $=20 \mu \mathrm{m}$ days postinoculation (dpi). Initially, small water-soaked lesions appeared on the primary root tips, which then progressed upward to produce wilting of the stems. The symptoms of MP313 infection in the cucurbits were similar to those in alfalfa, although the cucurbit crops exhibited more severe soft rot at their crowns. All the seedlings from the control plates remained asymptomatic (Fig. 4a).

The greenhouse trials demonstrated that MP313 could also cause disease on alfalfa plants grown in pots. Brown lesions were observed on the stem bases as early as 4 to $6 \mathrm{dpi}$, with nearly $85 \%$ of the plants becoming symptomatic at $10 \mathrm{dpi}$. Seedlings inoculated when 10 days old began to wither and lodge at 8 dpi (Fig. 4b), while the roots and stem bases of the 2-month-old plants turned brown and rotted (Fig. 4c). Again, the control plants exhibited no symptoms of infection. The results of a second independent experiment were similar (data not presented).

Samples were taken from both the control and infected plants but fungal colonies could only be isolated from the infected samples. The reisolated fungi produced colonies and conidiophores morphologically identical to those of the original field isolates used for the inoculation, thus fulfilling Koch's postulates and confirming that $M$. tabacinum was pathogenic to alfalfa.

Design of $M$. tabacinum-specific primers. The partial ITS sequence obtained during this study was used to identify a target site that was $100 \%$ conserved for M. tabacinum. The forward and reverse primers were designated Mt1F and Mt1R, respectively, and had the sequences $5^{\prime}$-CGACGATACTTCTGAGTGTTCT- ${ }^{\prime}$ and $5^{\prime}$ AATGCGAGGCTGATGCTA-3', respectively.

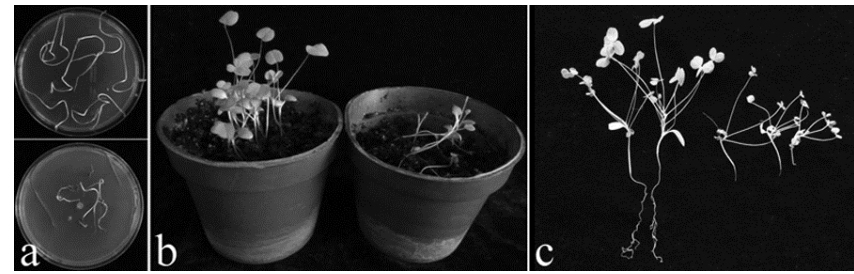

Fig. 4. Symptoms of Microdochium tabacinum rot in alfalfa Algonquin; a, seedlings inoculated with M. tabacinum MP313 after 15 days of dark incubation on water agar at $20^{\circ} \mathrm{C}$ (upper plate $=$ control); $\mathbf{b}, 10$-day-old plants 16 days postinoculation (dpi) with MP313 under greenhouse conditions (left = control); c, crown and root rot on 2-month-old plants $14 \mathrm{dpi}$ (left = control)

A $\begin{array}{llllllllllllllll}\mathrm{M} & 1 & 2 & 3 & 4 & 5 & 6 & 7 & 8 & 9 & 10 & 11 & 12 & 13 & 14 & 15\end{array}$

$400 \mathrm{bp}$

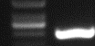

B

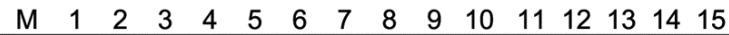

$400 \mathrm{bp}$

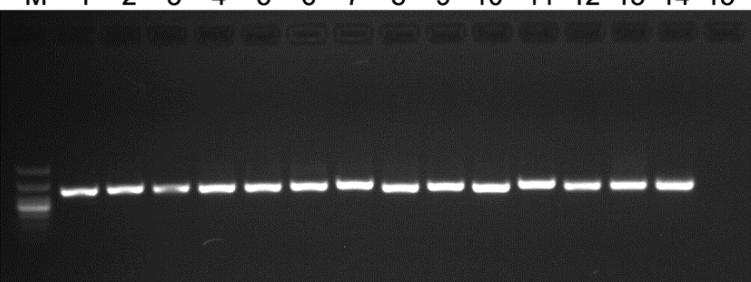

Fig. 5. Polymerase chain reaction analysis demonstrating the specificity of $A$, the Mt1F-Mt1R primer set, which was designed to amplify the internal transcribed spacer (ITS) region of Microdochium tabacinum ribosomal DNA, relative to $B$, the universal primers ITS4 and ITS5. Different lanes correspond to the following: M, 1kb DNA ladder; 1, M. tabacinum MP313; 2, Fusarium acuminatum; 3, F. equiseti; 4, F. oxysporum; 5 , F. semitectum; $6, F$. avenaceum; 7 , Colletotrichum destructivum; 8 , Phoma medicaginis; 9, Alternaria alternata; 10, Penicillium sp.; 11, Scopulariopsis brevicaulis; 12, Rhizoctonia solani; 13, M. nivale; 14, M. bolleyi; and 15, negative control (water). 
Specificity and sensitivity of the Mt1F- Mt1R primer set. The results of a GenBank BLAST search for the available ITS sequences were used during the design process to ensure that the $\mathrm{Mt} 1 \mathrm{~F}$ and Mt1R primers were unique to M. tabacinum. The specificity of the primers was subsequently tested using DNA from 13 fungal species (11 fungi associated with the root rot of alfalfa in Gansu province plus M. nivale and M. bolleyi; see Materials and Methods). The results of the analysis confirmed the specificity of the primers, with the 304-bp product only being amplified (Fig. 5A) from the isolate of M. tabacinum: MP313. In contrast, the universal primers ITS4 and ITS5 successfully amplified a 600-bp product from all the fungi tested (Fig. 5B).

Having confirmed the specificity of the primers, their sensitivity was tested using a dilution series of $M$. tabacinum template DNA, which revealed that concentrations as low as $20 \mathrm{fg} / \mu$ l could be used to amplify the 304-bp product (Fig. 6).

The primer set was then successfully used to amplify products from DNA extracted from roots of inoculated alfalfa plants (Fig. 7). No PCR products were recovered from any of the noninoculated control plants. Taken together, these results indicated that the $M$. tabacinum-specific primers $\mathrm{Mt} 1 \mathrm{~F}$ and $\mathrm{Mt} 1 \mathrm{R}$ could be used as a diagnostic tool to detect $M$. tabacinum infections in diseased alfalfa roots.

\section{Discussion}

The present study confirmed that $M$. tabacinum was one of the causal agents for crown and root rot of alfalfa (Longdong) in Gansu Province. M. tabacinum was previously classified as Cephalosporium tabacinum J.F.H. Beyma; Plectosporium tabacinum (J.F.H. Beyma) M.E. Palm, W. Gams \& Nirenberg; and Fusarium

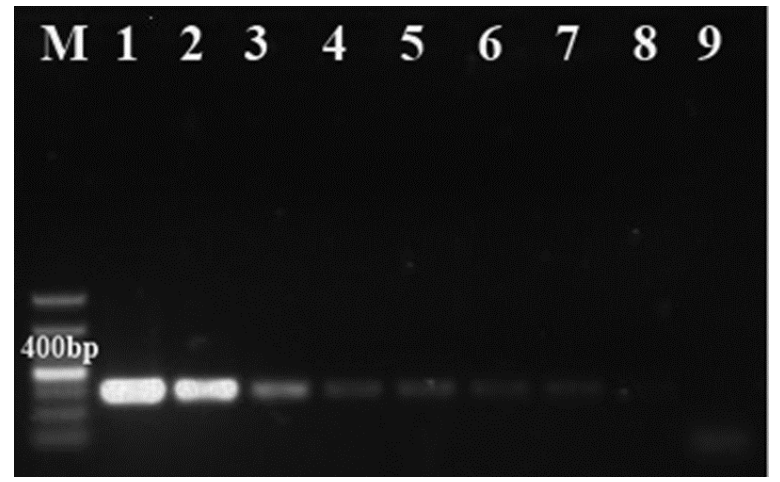

Fig. 6. Polymerase chain reaction analysis assessing the sensitivity of the Microdochium tabacinum-specific primers, Mt1F and Mt1R. Lanes 1-8 represent a diminishing concentration of $M$. tabacinum genomic DNA, as follows: $20 \mathrm{ng}, 2 \mathrm{ng}, 200$ pg, $20 \mathrm{pg}, 2 \mathrm{pg}, 200 \mathrm{fg}, 20 \mathrm{fg}$, and $2 \mathrm{fg}$. Lane 9 represents the negative control (water) and lane $\mathrm{M}$ contains a 1-kb DNA ladder.

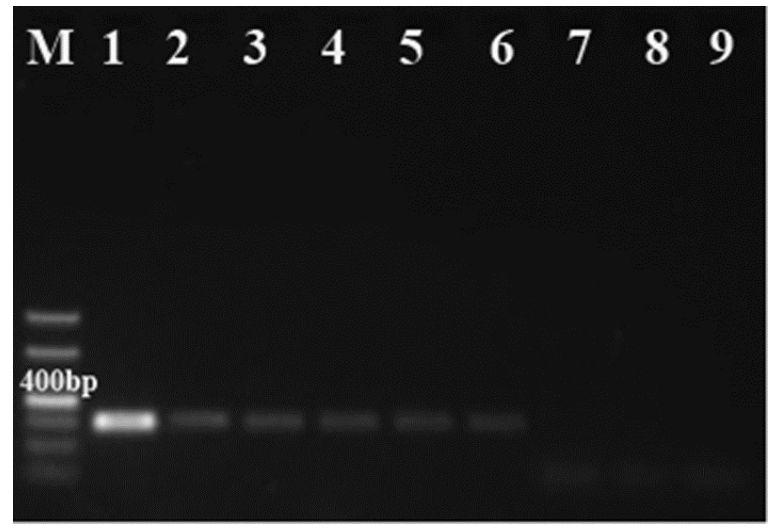

Fig. 7. Polymerase chain reaction analysis using the Mt1F-Mt1R primer set to detect the presence of Microdochium tabacinum in: lanes 2-6, diseased roots of Algonquin alfalfa ; lane 1, positive control; lanes 7 and 8 , negative controls (noninoculated roots); lane 9, negative control (water); and lane M, 1-kb DNA ladder. tabacinum (J.F.H. Beyma) W. Gams. Its teleomorph, Monographella cucumerina (Lindf.) Arx (44), previously classified as Venturia cucumerina Lindf., Plectosphaerella cucumeris Kleb., or Micronectriella cucumeris (Kleb.) C. Booth, is sometimes formed (32). Isolate MP313 was identified as Microdochium tabacinum by examination of its morphology and the molecular analysis of its rDNA (namely, its ITS and LSU sequences), an approach which has also been used to distinguish species of Microdochium in previous studies where teleomorphic structures were absent (7). The morphology of the conidia and phylogenetic analysis of MP313 indicated that it was closely related to $M$. tabacinum strains isolated from the roots of melon in Italy (7). The growth rate of the isolate on PDA plates in the dark at $25^{\circ} \mathrm{C}$ also agreed with descriptions of M. tabacinum (32). The pathogenicity of MP313 in alfalfa and a range of cucurbits was confirmed by pathogenicity assays, while its reisolation fulfilled Koch's postulates. To the best of our knowledge, this is the first report of $M$. tabacinum causing crown and root rot in alfalfa in China. Indeed the only previous report of $M$. tabacinum causing disease in alfalfa was the study of Pegg and Parry (33), in which F. tabacinum, a previous name for $M$. tabacinum, was isolated from fields in Kent, UK. However, M. tabacinum has previously been reported as an important pathogen that can cause severe disease in a wide range of plants (38). It is also known to be a common constituent of the rhizosphere of agricultural and meadow soils, where it is responsible for the decomposition of plant materials (32) and, thus, represents a constant source of inoculum.

M. tabacinum-specific primers (Mt1F and Mt1R) were designed from the ITS rDNA of MP313 and their specificity confirmed by PCR analysis using template DNA from one $M$. tabacinum isolate and 13 other fungi. The primers were capable of detecting $M$. tabacinum directly from infected plant material, which demonstrated their suitability for use as a diagnostic tool. Among the causal organisms that are associated with crown and root rot complex of alfalfa in this study, the effects of Fusarium spp., Phoma medicaginis, A. alternata, and Colletotrichum destructivum on alfalfa have been reported previously; for example, by Couture et al. (10), Rodriguez et al. (36), Guo et al. (16), Koch et al. (21), and Tai (40). Therefore, the current study mainly focused on one isolate of $M$. tabacinum originating from a single location in Gansu Province. However, further research is required to fully understand the etiology and epidemiology of crown and root rot in Chinese alfalfa populations. A previous survey (16), which examined the root-invading fungi of alfalfa in the Loess Plateau, identified 23 different fungi associated with the roots of alfalfa, the five most common being $F$. oxysporum, Selinia sp., P. medicaginis, F. solani, and Cylindrocarpon destructans, with the isolated frequency of $17.0,15.4,9.5,6.7$, and $6.6 \%$, respectively. The current study also found Fusarium, Phoma, and Alternaria spp. to be common in alfalfa root samples. However, the five most common fungi isolated, in order of decreasing frequency of isolation, were $F$. semitectum (32.7\%), P. medicaginis (13.7\%), F. equiseti (13.1\%), A. alternata $(11.3 \%)$, and $F$. acuminatum $(6.5 \%)$. Further studies evaluating the effects of $M$. tabacinum on alfalfa stand longevity and nutritional value, as well as its interactions with other pathogens, are required to confirm the agronomic importance of $M$. tabacinum in alfalfa cultivation.

\section{Acknowledgments}

This work was supported financially by the National Key Basic Research Program (973) of China (2014CB138700) and China Agricultural Research System (CARS-035). We thank Yanrong Wang for supplying the alfalfa seed; and Suqin He, Pei Tian, Xingxu Zhang, Zhixin Zhang, and Zhenfen Zhang for their technical assistance.

\section{Literature Cited}

1. Akamatsu, H. O., Chilvers, M. I., and Peever, T. L. 2008. First report of spring black stem and leaf spot of alfalfa in Washington State caused by Phoma medicaginis. Plant Dis. 92:833.

2. Altier, N., and Thies, J. A. 1995. Identification of resistance to Pythium seedling diseases in alfalfa using a culture plate method. Plant Dis. 79:341346. 
3. Anonymous. 1960. Index of plant diseases in the United States. U. S. Dep. Agric. Agric. Handb. 165:1-531.

4. Antonopoulos, D. F., Elena, K., and Tjamos, E. C. 2003. First report of Fusarium wilt of alfalfa in Greece. Plant Dis. 87:751.

5. Basu, P. K. 1983. Survey of eastern Ontario alfalfa fields to determine common fungal diseases and predominant soil-borne species of Pythium and Fusarium. Can. Plant Dis. Surv. 63:51-54.

6. Booth, C. 1971. The Genus Fusarium. Commonwealth Mycological Institute, Kew, Surrey, England.

7. Carlucci, A., Raimondo, M. L., Santos, J., and Phillips, A. J. L. 2012. Plectosphaerella species associated with root and collar rots of horticultural crops in southern Italy. Persoonia 28:34-48.

8. Chen, Y., Min, J. C., Xiao, F., Mu, H. T., and Abdu, R. H. 1989. The preliminary study on root rot diseases of alfalfa in Xingjiang Uygur Autonomous Region. Grassl. China 2:71-73. (In Chinese with English abstract)

9. Chi, C. C., Chiders, W. R., and Hanson, E. W. 1964. Penetration and subsequent development of three Fusarium species in alfalfa and red clover. Phytopathology 54:434-437.

10. Couture, L., Dhont, C., Chalifour, F.-P., Drapeau, R., Tremblay, G., Castonguay, Y., Bélanger, G., and Nadeau, P. 2002. Fusarium root and crown rot in alfalfa subjected to autumn harvests. Can. J. Plant Sci. 82:621624 .

11. Domsch, K. H., Gams, W., and Anderson, T.-H. 1980. Compendium of Soil Fungi, Vol. 1. Academic Press, New York.

12. Doole, G. J., and Pannell, D. J. 2008. Role and value of including lucerne (Medicago sativa L.) phases in crop rotations for the management of herbicide-resistant Lolium rigidum in Western Australia. Crop Prot. 27:497-504.

13. Dotzenko, A., and Ahlgren, G. H. 1950. Response of alfalfa in an alfalfabromegrass mixture to various cutting treatments. Agron. J. 42:246-247.

14. Erwin, D. C. 1954. Relation of Stagnospora, Rhizoctonia and associated fungi to crown rot of alfalfa. Phytopathology 44:137-144.

15. Gray, F. A., Haaland, R. L., Clark, E. M., and Ball, D. M. 1980. Diseases of alfalfa in Alabama. Plant Dis. 64:1015-1017.

16. Guo, Y. X., Nan, Z. B., Li, C. J., Shen, Y. Y., Gao, C. Y., Bellotti, W. D., and Chen, W. 2004. Root-invading fungi of lucerne and winter wheat in the rotation system on the Loess Plateau. Acta Ecol. Sin. 24:486-494. (In Chinese with English abstract)

17. Hall, T. A. 1999. BioEdit: A user-friendly biological sequence alignment editor and analysis program for Windows 95/98/NT. Nucleic Acids Symp. Ser. 41:95-98.

18. Hancock, J. G. 1985. Fungal infection of feeder rootlets of alfalfa. Phytopathology 75:1112-1120.

19. Hwang, S. F., and Flores, G. 1987. Effects of Cylindrocladium gracile, Fusarium roseum and Plenodomus meliloti on crown and root rot, forage yield, and winterkill of alfalfa in northeastern Alberta. Can. Plant Dis. Surv. 67:31-33.

20. Hwang, S. F., Gossen, B. D., Turnbull, G. D., Chang, K. F., and Howard R. J. 2002. Seedbed preparation, timing of seeding, fertility and root pathogens affect establishment and yield of alfalfa. Can. J. Plant Sci. 82:371-381.

21. Koch, S. H., Baxter, A. P., and Knox-Davies, P. S. 1989. Identity and pathogenicity of Colletotrichum species from Medicago sativa in South Africa. Phytophylactica 21:69-78.

22. Latta, R. A., Blacklow, L. J., and Cocks, P. S. 2001. Comparative soil water, pasture production, and crop yields in phase farming systems with lucerne and annual pasture in Western Australia. Aust. J. Agric. Res. 52:295-303.

23. Latunde-Dada, A. O., Bailey, J. A., and Lucas, J. A. 1997. Infection process of Colletotrichum destructivum O'Gara from lucerne (Medicago sativa L.). Eur. J. Plant Pathol. 103:35-41.

24. Leath, K. T. 1990. Crown and root rot complexes. Pages 43-44 in: Compendium of Alfalfa Diseases, 2nd ed. D. L. Stuteville and D. C. Erwin, eds. American Phytopathological Society, St. Paul, MN.
25. Li, M. Q. 2003. Comparative pathogenicity of isolates of Fusarium spp. and cultivars resistance in alfalfa. Grassl. China 25:39-43. (In Chinese with English abstract)

26. McKenzie, J. S., and McLean, G. E. 1984. A field test for assessing the winter hardiness of alfalfa in northwestern Canada. Can. J. Plant Sci. 64:917-924.

27. Michaud, R., Lehnan, W. F., and Rumbaugh, M. D. 1988. World distribution and historical development. Pages 25-124 in: Alfalfa and Alfalfa Improvement. A. A. Hanson, D. K. Barnes, and R. R. Hill, Jr., eds. ASA-CSSASSSA, Madison, WI

28. Nan, Z. B. 1995. Fungicide seed treatments of sainfoin control seed-borne and root-invading fungi. N. Z. J. Agric. Res. 38:413-420.

29. Nan, Z. B., and Li, C. J. 1994. Fungal disease of pasture plants recorded in China-a check list. Pratacult. Sci. (Suppl.):12-13. (In Chinese with English abstract)

30. Nan, Z. B., and Yuan, B. H. 1994. Diseases of lucerne growing at Altai Prefecture, Xingjiang. Pratacult. Sci. 11:15-18. (In Chinese with English abstract)

31. Nelson, P. E., Toussoun, T. A., and Marasas, W. F. O. 1983. Fusarium species: An Illustrated Manual for Identification. Pennsylvania State University, University Park.

32. Palm, M. E., Gams, W., and Nirenberg, H. I. 1995. Plectosporium, a new genus for Fusarium tabacinum, the anamorph of Plectosphaerella cucumerina. Mycologia 87:397-406.

33. Pegg G. F., and Parry D. W. 1983. Infection of lucerne (Medicago sativa) by Fusarium species. Ann. Appl. Biol. 103:45-55.

34. Radović, J., Sokolović, D., and Marković, J. 2009. Alfalfa-most important perennial forage legume in animal husbandry. Biotech. Anim. Husb. 25:465-475.

35. Reeleder, R. D. 1982. Fungi recovered from diseased roots and crowns of alfalfa in north central Alberta and the relationship between disease severity and soil nutrient levels. Can. Plant Dis. Surv. 62:21-27.

36. Rodriguez, R., Leath, K. T., and Hill, R. R., Jr. 1990. Pathogenicity of Phoma medicaginis var. medicaginis to roots of alfalfa. Plant Dis. 74:680-683.

37. Saitou, N., and Nei, M. 1987. The neighbor-joining method: A new method for reconstructing phylogenetic trees. Mol. Biol. Evol. 4:406-425.

38. Sanchez-Vallet, A., Ramos, B., Bednarek, P., López, G., PiślewskaBednarek, M., Schulze-Lefert, P., and Molina, A. 2010. Tryptophan-derived secondary metabolites in Arabidopsis thaliana confer non-host resistance to necrotrophic Plectosphaerella cucumerina fungi. Plant J. 63:115-127.

39. Simmons, E. G., and Roberts, R. G. 1993. Alternaria themes and variations 73. Mycotoxon 48:109-140.

40. Tai, F. L. 1979. Colletotrichum destructivum O'Gara. Page 917 in: Sylloge Fungorum Sinicorum. Science Press, Academia Sinica, Beijing.

41. Tamura, K., Dudley, J., Nei, M., and Kumar, S. 2007. MEGA4: Molecular Evolutionary Genetics Analysis (MEGA) software version 4.0. Mol. Biol. Evol. 24:1596-1599.

42. Thompson, J. D., Gibson, T. J., Plewniak, F., Jeanmougin, F., and Higgins, D. G. 1997. The CLUSTAL_X windows interface: Flexible strategies for multiple sequence alignment aided by quality analysis tools. Nucleic Acids Res. 25:4876-4882

43. Vilgalys, R., and Hester, M. 1990. Rapid genetic identification and mapping of enzymatically amplified ribosomal DNA from several Cryptococcus species. J. Bacteriol. 172:4239-4246.

44. von Arx, J. A. 1984. Notes on Monographella and Microdochium. Trans. Br. Mycol. Soc. 83:373-374.

45. White, T. J., Bruns, T., Lee, S., and Taylor, J. 1990. Amplification and direct sequencing of fungal ribosomal RNA genes for phylogenetics. Pages 315-322 in: PCR Protocols: A Guide to Methods and Applications. M. A. Innis, D. H. Gelfand, J. J. Sninsky, and T. J. White, eds. Academic Press, San Diego, CA 